\title{
A culturally sensitive Transition Assistance Program for stroke caregivers: Examining caregiver mental health and stroke rehabilitation
}

\author{
Paul B. Perrin, MS; ${ }^{1-2 *}$ Andrew Johnston, MPH; ${ }^{1}$ Bruce Vogel, PhD; ${ }^{1,3}$ Martin Heesacker, PhD; ${ }^{1-2}$ Mercedes \\ Vega-Trujillo, BSOT; ${ }^{4}$ Jane Anderson, PhD, ARNP; ${ }^{5-7}$ Maude Rittman, PhD, RN ${ }^{1,8}$ \\ ${ }^{1}$ Department of Veterans Affairs (VA), Rehabilitation Outcomes Research Center Research Enhancement Award Program, \\ North Florida/South Georgia Veterans Health System, Gainesville, FL; ${ }^{2}$ Department of Psychology, University of \\ Florida, Gainesville, FL; ${ }^{3}$ Department of Epidemiology and Health Policy Research, Health Science Center, College of \\ Medicine, University of Florida, Gainesville, FL; ${ }^{4}$ VA, Physical Medicine and Rehabilitation Service, Caribbean \\ Healthcare System, San Juan, Puerto Rico; ${ }^{5}$ Michael E. DeBakey VA Medical Center, Stroke Center, Houston, TX; \\ ${ }^{6}$ Baylor College of Medicine, Houston, TX; ${ }^{7}$ Prairie View A\&M, College of Nursing, Houston, TX; ${ }^{8}$ College of Nursing, \\ University of Florida, Gainesville, FL
}

\begin{abstract}
This study developed and implemented the Transition Assistance Program (TAP) for stroke caregivers. The program is composed of (1) skill development, (2) education, and (3) supportive problem solving. Sixty-one dyads $(n=122)$ participated: thirty-nine from Puerto Rico and twenty-two from Texas. Participants were randomly assigned to the TAP treatment or a control group. As caregiver satisfaction with the TAP increased, strain and depression decreased, and caregivers reported a very high rate of program satisfaction (9.5 out of 10). The TAP effectively reduced caregiver strain at the 3month follow-up. When controlling for baseline differences, we found that the treatment group had lower depression ( $p=$ 0.07 ) than the control group at follow-up and that the TAP may have had a preventative effect on depression for caregivers who had not been depressed at discharge, although this visual trend did not reach statistical significance. Among veterans with low functioning at baseline, veterans whose caregivers had received the TAP improved in functioning more than did veterans whose caregivers had been in the control group, although this visual trend was not significant. Functioning in veterans with stroke was also significantly linked to caregiver satisfaction with the TAP. The findings from the current study warrant further evaluation of the TAP intervention.
\end{abstract}

Key words: burden, caregivers, cultural sensitivity, depression, functional status, home care, strain, stroke, support, transition.

\section{INTRODUCTION}

Stroke is the leading cause of serious long-term disability in the United States, with more than 4 million people living with the effects of stroke [1-2]. Findings from the 1999 National Long-Term Survey and the Informal Caregiver Survey support initiatives to reduce caregiver stress as a strategy to prevent or defer nursing home entry [3]. Currently, approximately 80,000 veterans receiving healthcare in the Veterans Health Administration (VHA) are living with stroke [4]. It is estimated that approximately 9,000 to 11,000 additional veterans are hospitalized annually with a new stroke [4-5]. Roughly 80 percent of

Abbreviations: CESD-10 = Center for Epidemiologic Studies Depression (scale), FIM = Functional Independence Measure, IRB = institutional review board, $\mathrm{SD}=$ standard deviation, TAP $=$ Transition Assistance Program, VA $=$ Department of Veterans Affairs, VHA = Veterans Health Administration.

* Address all correspondence to Paul B. Perrin, MS; University of Florida, North Florida/South Georgia Veterans Health System, Rehabilitation Outcomes Research Center, PO Box 112250, Gainesville, FL 32611-2250; 352-392-0601; fax: 352-392-7985. Email: pbperrin@ufl.edu

DOI:10.1682/JRRD.2009.10.0170 
individuals with stroke are discharged home and live for at least 5 years poststroke, shifting a large amount of continuing care to informal caregivers [6]. Informal caregivers play a key role in assisting people with stroke who need long-term care to sustain independent living in their own homes and communities. A top VHA priority is to improve the quality of life of veterans who are receiving long-term care, which includes informal home care from caregivers. The current pilot study contributes to this priority by evaluating an evidence-based caregiver intervention.

Stroke is a triggering event in which family members focus initially on survival during the acute phase of treatment. When family members see that the loved one will survive, they anticipate changes needed after discharge, and the individuals with stroke begin coping with changes in functional abilities and body image [7-8]. Research has found that the experiences of individuals with stroke during the first month postdischarge involve adapting to changes in their sense of self, connections with others, and community participation [8-9]. Managing multiple psychosocial changes in the first month postdischarge is often very difficult [10], and research supports the need for interventions during the immediate postdischarge period [11].

Interventions addressing education, support, and problem solving are effective in improving the mental health of individuals with stroke and stroke caregivers [11-16]. Informal caregivers need information about the experiences of people with stroke and about how to manage stroke recovery effectively, thereby promoting better quality of life for people with stroke [8]. A number of studies have examined the effects of interventions for stroke caregivers. For example, research has demonstrated the effectiveness of social problem solving therapy by telephone in improving stroke caregivers' mental health, social functioning, preparedness, vitality, and problem solving skills [17]. Other research has highlighted the importance of routine and real-time telephone interventions in which healthcare providers supply information about stroke [18]. Similarly, stroke caregiver support, education, and training programs are effective in reducing stoke caregiver stress levels [19]. And largescale reviews and meta-analyses have generally suggested that caregiver education, counseling, and support interventions by telephone and in person are effective in reducing caregiver stress; improving family functioning, caregiver mental health, psychosocial functioning, and knowledge; and reducing the anxiety and depression of people with stroke [11,20-22].

The fundamental premise for the intervention in the current study is that the stronger a caregiver's ability to provide quality informal care, the better the rehabilitation of the individual with stroke will be [23-24]. The research question that drove this study is "Do videophone educational and supportive problem solving interventions for stroke caregivers improve caregiver mental health and functioning of individuals with stroke following discharge home?” This study specifically builds on previous research by attempting to create a culturally sensitive educational and supportive problem solving videophone intervention for stroke caregivers in Puerto Rico and the U.S. mainland that is cost-effective and convenient, both for healthcare providers and caregivers. To date, no known studies have been published on videophone interventions for stroke caregivers.

\section{CAREGIVER TRANSITION ASSISTANCE PROGRAM}

In the current study, we used the caregiver guidebook, A Guidebook for Caregivers of Veterans Post Stroke (English or Spanish versions), which was specifically developed for caregivers of veterans poststroke from both Puerto Rico and the U.S. mainland. Based on the literature and on stroke statistics from the American Stroke Association, we developed two versions of the caregiver guidebook - one for the U.S. mainland and one in Spanish that was culturally relevant for Puerto Rican veterans and caregivers. The guidebook is composed of three chapters:

- Chapter 1 reviews the basics of stroke, including a description of what a stroke is, how to recognize signs of stroke or transient ischemic attack, and how to prevent future strokes.

- Chapter 2 provides information about stroke caregiving to assist caregivers in providing care to veterans after discharge.

- Chapter 3 provides an overview of the recovery experiences of individuals with stroke and of the common experiences of stroke, such as disability, disruption in sense of self, social isolation, and depression.

The guidebook is the primary educational tool used in the Transition Assistance Program (TAP) caregiver pilot program. An extensive formative and summative 
evaluation of the caregiver guidebook was employed that included focus groups with clinicians and stroke caregivers in San Juan, Puerto Rico; Indianapolis, Indiana; and Gainesville, Florida. The completed guidebook was then sent to a number of stroke nurses across the United States in the VHA, who gave quantitative feedback suggesting that the information in the guidebook would be relevant and appropriate for caregivers of veterans poststroke. After this process, the caregiver guidebook was ready for further evaluation in the current pilot project.

The TAP is a brief intervention that has three components: (1) skill development, (2) education, and (3) supportive problem solving using videophone technology. The TAP is focused on the transition period and begins just prior to discharge from the hospital to home. The TAP includes one face-to-face meeting with caregivers prior to discharge. Following discharge, four videophone calls are made to the caregivers. In weeks 1 and 2, caregivers receive a videophone call each week, and in weeks 4 and 6, they receive additional calls. The TAP is described in detail in the Appendix (available online only). The demonstration pilot program was conducted at the Stroke Specialty Rehabilitation Program, Department of Veterans Affairs (VA) Caribbean Healthcare System, San Juan, Puerto Rico, and the Michael E. DeBakey VA Stroke Center, Houston, Texas. These two centers have the highest volume of stroke treatment in the VHA.

\section{METHODS}

The TAP pilot project used an experimental design with random assignment of participants to two groups, a control group receiving the standard of care and a treatment group receiving the standard of care and the TAP.

\section{Participants}

The pilot TAP program was implemented at the two sites for a 14-month enrollment period. During the 14 months, veteran-caregiver dyads who met study criteria were randomly assigned to a treatment or control group. Initially, 89 dyads enrolled in the study, but 3 in Houston were unable to continue participating because of power loss after a hurricane, 1 dyad withdrew because the veteran's health improved to the point that he no longer needed a caregiver, 2 dyads withdrew because the veterans were admitted to nursing homes, 1 dyad failed to meet the scheduled TAP intervention appointments, 2 dyads moved away and were unavailable for contact, 1 dyad withdrew because of the veteran's unrelated death, and 1 dyad withdrew for personal reasons unrelated to the study. Additionally, due to issues with funding for this project, we were unable to amass all of the follow-up data from 17 dyads, who as a result were excluded from analyses. Data from 61 dyads were analyzed: 39 from Puerto Rico and 22 from Houston, Texas.

Table 1 provides demographic information on caregivers who were included in the current analyses, and Table 2 provides demographic data on the veterans. Of the 61 dyads with complete data, the average ( \pm standard deviation [SD]) age of caregivers was $58.5 \pm 12.0$ years and 91.8 percent were women. The average age of veterans was $69.4 \pm 10.2$, and 95.1 percent were men. Compared with Texans, Puerto Rican veterans had a higher mean age (71.3 vs 65.6). This was also true for Puerto Rican caregivers (59.0 vs 57.6), although by a smaller margin. Puerto Rican caregivers had fewer mean years of schooling than Texans (12.6 vs 13.7), while the veterans in each location had no appreciable difference in their mean years of schooling (12.9 vs 12.8). While the racial/ ethnic makeup of the Puerto Rican caregivers was largely homogenous, with 97.4 percent identifying as Puerto Rican/ Latino, the caregivers from Houston were 45.5 percent black and 40.9 percent white. Comparing familial relationship of the caregiver to the veteran, Texans had a slightly higher percentage of dyad-spouses (approximately $77.0 \%$ vs $66.0 \%$ ), but no caregivers who were the parent of the veteran. In contrast to Texas, caregivers in Puerto Rico were slightly less likely to live in the same home as the veteran (77.0\% vs $86.4 \%$ ).

\section{Veteran Inclusion Criteria}

All veterans who were both treated for stroke and anticipating being discharged home during the 14-month enrollment period were considered for program participation if they met the following criteria: (1) had a caregiver and gave permission for us to invite their caregiver to participate in the program, (2) signed informed consent giving permission to obtain demographic and health information, and (3) had the ability to communicate over the telephone for data collection on veteran outcomes at 3 months postdischarge. All dyads were enrolled after acute care and during inpatient rehabilitation. Although procedures were in place to collect data with self-administered paper-pencil reports via postal mail for aphasic patients, these were not needed. 
JRRD, Volume 47, Number 7, 2010

Table 1.

Caregiver demographics. Data presented as frequency_percentage (n)—unless otherwise noted.

\begin{tabular}{|c|c|c|c|}
\hline \multirow{2}{*}{ Demographic } & \multirow{2}{*}{ Total $(n=61)$} & \multicolumn{2}{|c|}{ Remote Site } \\
\hline & & PR $(n=39)$ & TX $(n=22)$ \\
\hline Age (yr) (mean \pm SD) & $58.5 \pm 12.0$ & $59.0 \pm 13.1$ & $57.6 \pm 9.9$ \\
\hline \multicolumn{4}{|l|}{ Employment } \\
\hline Full-Time & $32.8(20)$ & $30.8(12)$ & $36.4(8)$ \\
\hline Part-Time & $9.7(6)$ & $5.1(2)$ & $18.2(4)$ \\
\hline \multicolumn{4}{|l|}{ Race/Ethnicity } \\
\hline African American/Black & $16.3(10)$ & $0(0)$ & $45.5(10)$ \\
\hline Asian American & $1.6(1)$ & $0(0)$ & $4.5(1)$ \\
\hline Non-Hispanic Caucasian/White & $16.4(10)$ & $2.6(1)$ & $40.9(9)$ \\
\hline Hispanic/Latino Puerto Rican & $62.3(38)$ & $97.4(38)$ & $0(0)$ \\
\hline Parent & $4.9(3)$ & $7.7(3)$ & $0(0)$ \\
\hline Daughter/Son & $16.4(10)$ & $17.9(7)$ & $13.6(3)$ \\
\hline Other Family & $6.6(4)$ & $5.1(2)$ & $9.0(2)$ \\
\hline Years of School (mean \pm SD) & $13.0 \pm 2.9$ & $12.6 \pm 3.3$ & $13.7 \pm 2.2$ \\
\hline
\end{tabular}

Table 2.

Veteran demographics. Data presented as frequency_-percentage $(n)$ —unless otherwise noted.

\begin{tabular}{lccc}
\hline \multicolumn{1}{c}{ Demographic } & Total $(\boldsymbol{n}=\mathbf{6 1})$ & Remote Site & TX (n= 22) \\
\cline { 2 - 4 } Age (yr) (mean \pm SD) & $69.4 \pm 10.2$ & $71.3 \pm 10.3$ & $65.6 \pm 9.3$ \\
Sex: Male & $95.1(58)$ & $100(39)$ & $86.4(19)$ \\
Race/Ethnicity & & & \\
$\quad$ African American/Black & $18.0(11)$ & $0(0)$ & $50.0(11)$ \\
Asian American & $0(0)$ & $0(0)$ & $0(0)$ \\
Non-Hispanic Caucasian/White & $13.1(8)$ & $2.6(1)$ & $0(0)$ \\
Hispanic/Latino Puerto Rican & $60.7(37)$ & $04.9(37)$ & $13.6(3)$ \\
$\quad$ Hispanic/Latino Mexican & $4.9(3)$ & $0(0)$ & $2.5(1)$ \\
$\quad$ Hispanic/Latino Other & $1.6(1)$ & $1.9(1)$ & $0(0)$ \\
Other & $1.6(1)$ & $12.9 \pm 2.5$ & $12.8 \pm 2.2$ \\
Years of School (mean \pm SD) & $12.9 \pm 2.4$ &
\end{tabular}

\section{Caregiver Inclusion Criteria}

All caregivers of veterans who were discharged home were eligible for participation in the program if the veteran agreed that their caregivers could participate and if they met the following criteria: (1) had a landline telephone in the home and were able to talk on the telephone and (2) signed informed consent to participate in the program.

\section{Enrollment Procedure}

Clinicians working on the rehabilitation units informed veterans of the program and of the opportunity for them and their caregivers to participate. If the dyad was interested, the project manager discussed the program with the veteran and obtained informed consent. The veteran consent included their permission for the caregiver 
to participate. The project manager contacted the caregiver, explained the program, and invited the caregiver to participate. Participant dyads were randomly assigned to the treatment or control group. A table of randomized numbers was provided to each site for assigning dyads to either group as they were enrolled. Demographic and baseline data were collected from veterans and caregivers following enrollment.

\section{Instruments}

\section{Caregiver Strain}

The Caregiver Strain Index is a 13-item tool that measures strain related to care provision [25-26]. Major domains include Employment, Financial, Physical, Social, and Time. A score of 7 positive responses indicates a greater level of strain. Internal consistency reliability is high $(\alpha=0.86)$ and construct validity is supported by correlations with physical and emotional caregiver health status and with self-reports of caregiving experiences.

\section{Caregiver Depression}

Depression was assessed using a short 10 -item version of the Center for Epidemiologic Studies Depression (CESD-10) scale [27]. The CESD-10 showed good predictive accuracy when compared with the full-length 20 -item version $(\kappa=0.97, p<0.001)$ [27]. The CESD-10 showed expected positive correlations with poorer health status scores $(r=0.37)$. The measure has been reported as reliable, valid, and sensitive to change over time [27]. The CESD-10 has been used in general, patient, and older adult populations, including veterans [28]. This brief measure produces a continuous score that can alternately be used as a dichotomous measure, with a threshold of 10 points (equivalent to the full 20-item scale vs an alternate threshold of 20 points), for classifying subjects with clinically relevant symptoms of depression. Caregiver depression is a key measure hypothesized to affect health-related quality of life and quality of informal care [23-24].

\section{Caregiver Satisfaction}

A form adapted from the VA Care Coordination and Home Telehealth Patient Satisfaction Survey asked caregivers to rate their satisfaction with the use of telehealth technology and each aspect of the pilot program on a 5-point Likert scale, with 1 being not at all satisfied and 5 being completely satisfied.

\section{Veteran Functional Status}

Functional status was assessed at baseline using the Functional Independence Measure (FIM). The FIM has a total score and six subscale scores: Self-Care, Sphincter Control, Transfer Capability, Locomotion, Communication, and Social Cognition. The FIM is an indication of the amount of assistance needed by the person recovering from disability. The FIM is the most widely used method of assessing function in persons with a disability. The FIM consists of 18 items and 7 response alternatives per item [29-31]. Scores range from 18 to 126, with higher scores indicating more effective functioning. The reliability of the FIM is well established. In a meta-analysis study by Ottenbacher et al., the median interrater reliability coefficient for the total FIM was 0.95, the median test-retest reliability coefficient was 0.95 , and the equivalence reliability coefficient was 0.92 [32]. Multiple studies have demonstrated validity of the FIM [33-41]. The FONE FIM (telephone version of the FIM) was used in each current study to collect data on functional status from the veteran at 3 months postdischarge. The FONE FIM is useful for monitoring functional status in community contexts, such as home health care, and has excellent psychometric properties [42]. The Motor FIM subscale score was used for the current analyses.

\section{Data Collection}

At each site, a research assistant enrolled participants and collected and managed data. Additionally, each site hired a clinical interventionist to provide the intervention. The interventionist at the San Juan site was a masterslevel physical therapist, and the interventionist at the Houston site was a doctoral-level nurse practitioner. Both the principal investigator and the project manager gave in-person procedural training for data collection and instrument use to all study staff at both collection sites. All staff received the same cross-training in order to increase the staff's familiarity with all aspects of the study. This training involved telephone role playing, conceptual discussions regarding the purpose of the TAP, interpersonal education for interacting with caregivers and veterans, technical education on the videophones, and education about the caregiver guidebook. The research assistants collected data at three time points: baseline while the veteran was in the hospital and at 1 and 3 months postdischarge via telephone interviews. The final measure occurred 6 weeks after the final videophone call. Data from veterans were collected twice: 
baseline while in hospital and at 3 months postdischarge via telephone.

\section{RESULTS}

\section{Caregiver Satisfaction}

The sum of the four items assessing satisfaction with the TAP program significantly inversely correlated with caregiver strain $(r=-0.44, p<0.01)$ and depression $(r=$ $-0.53, p<0.01$ ), suggesting that as caregiver satisfaction with the TAP program increased, the negative psychosocial factors of strain and depression decreased. When coupled with the very high rate of program satisfaction, which was 9.5 out of a maximum of $10(\mathrm{SD}=0.95)$, this pattern suggests that TAP participation helped caregivers cope.

\section{Caregiver Depression}

We examined differences in depression scores at baseline, 1 month, and 3 months by using a regression model in which the independent variables were treatment (control or treatment), time (baseline, 1-month follow-up, and 3-month follow-up), and the treatment $\times$ time interaction. The dependent variable was depression score. A treatment main effect would identify general differences in depression between the treatment and control groups, a time main effect would identify changes in depression over time, and a treatment $\times$ time interaction effect would identify differential changes by treatment group in depression scores over time. The full model just described failed to detect any statistically significant treatment effects.

However, a simplified version of the full model did find statistically significant treatment effects (Table 3). The purpose of this model was to determine whether significant treatment effects on depression scores would be found after controlling for baseline differences in depression between the treatment and control group. In the simplified model, the independent variables were treatment group (control or treatment) and the treatment $\times$ time interaction. The independent variable was again depres- sion score. This model omitted the 1-month follow-up data in order to decrease power loss from lower degrees of freedom, which is particularly problematic in our pilot sample of 61 dyads. Additionally, we increased our alpha threshold to 0.10 , adjusting for the pilot nature of our sample. In this simplified model, the treatment $\times$ time interaction was statistically significant at the 0.10 level, which suggests that after 3 months the treatment group exhibited lower depression scores than the control group when controlling for baseline differences. The treatment $x$ time coefficient of -1.32 corresponds to a 73 percent lower depression score in the treatment group compared with the control group.

Using the thresholds for depression provided by the instrument, we also examined two groups of caregiversthose who scored below the depression cutoff and those who scored above the depression cutoff (Figures 1 and 2). In terms of statistically nonsignificant visual trends, the TAP appears to have had an attenuating effect on depression among caregivers. For caregivers who were "not depressed" at baseline (Figure 2), depression scores in the treatment group remained low at 3 months, whereas depression in the control group showed a marked increase. However, it is important to emphasize that this effect was not statistically significant, likely because of the small sample size, and should be interpreted with extreme caution.

\section{Caregiver Strain}

Caregiver strain (Figure 3), measured at 1 month and 3 months postdischarge, was significantly different between treatment and control groups. Caregivers who were in the treatment group experienced a decrease in strain from 1 to 3 months (mean \pm SD change in strain $=-1.64 \pm 3.31$ ), whereas control participants increased in strain from 1 to 3 months (mean \pm SD change in strain $=2.00 \pm 6.26$ ), and this net change between the two groups was statistically significant, $t$ (36.88, unequal variances) $=2.61, p=$ 0.01 . Caregiver strain worsened across time when untreated, whereas strain was reduced in caregivers in the

Table 3.

Ordinary least squares regression of natural logarithm of depression score against treatment group and time.

\begin{tabular}{lccc}
\hline \multicolumn{1}{c}{ Variable } & Coefficient & t-Statistic & $\boldsymbol{p}$-Value \\
\hline Intercept & 1.63 & 3.83 & $<0.000$ \\
Treatment & -0.50 & -0.81 & 0.42 \\
Treatment $\times$ Time & -1.32 & -1.81 & 0.07 \\
Adjusted $R^{2}$ & 0.03 & - & - \\
$p$-Value of F-Test & 0.042 & - & - \\
\hline \hline
\end{tabular}




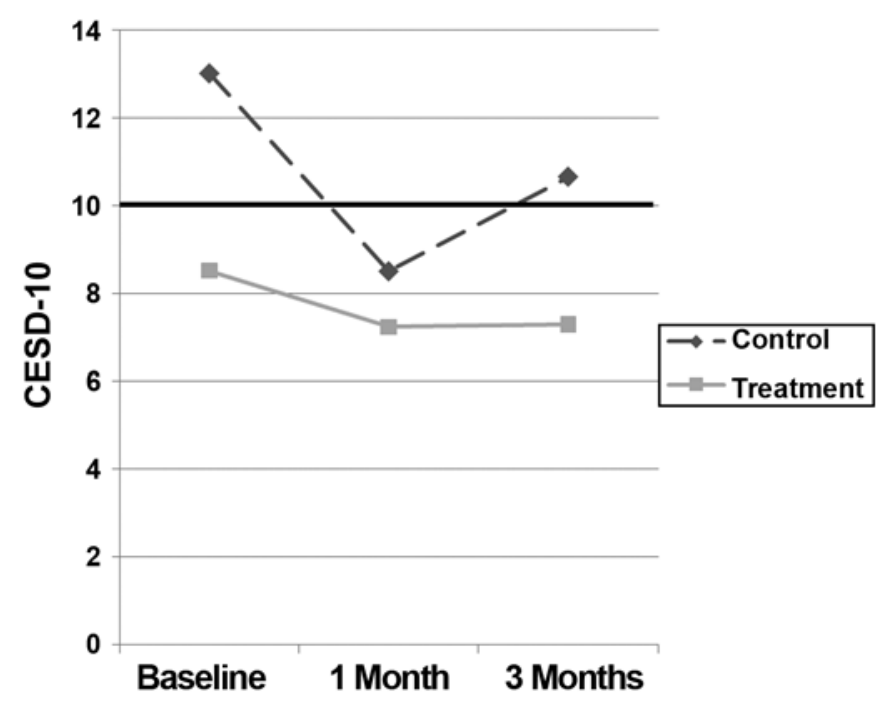

Figure 1.

Depression, as measured by Center for Epidemiologic Studies Depression (CESD-10) scale, scores for total sample by treatment group $(n=61)$. Scores reported for each time frame represent mean scores for each respective group. Bold line represents threshold value (10) for depression on this instrument.

treatment group. This result suggests that after participating in the TAP program, caregivers experienced less strain.

\section{Veteran Functional Status}

Veteran Motor FIM score, a measure of poststroke motor functioning, was significantly linked to caregiver satisfaction with the TAP program $(r=0.46, p<0.01, n=$ 33 ), suggesting that as caregiver satisfaction with the program increased, so did veteran functioning, although this effect may or may not be causal. Another interesting finding is that caregiver psychosocial factors were themselves associated with veteran motor function. These associations occurred across TAP participants and nonparticipants alike (caregiver self-efficacy $r=0.44, p<$ $0.001, n=58$; caregiver strain $r=-0.33, p<0.01, n=59$; caregiver burden $r=-0.28, p<0.05, n=59$ ) and suggest, as prior research has, that as caregiver psychosocial functioning increases, so does veteran poststroke functioning, although the relationship is often reciprocal [23-24].

Exploratory analysis of change in Motor FIM scores suggests that the treatment may have had an effect on veterans' functional ability among veterans with low baseline Motor FIM scores (FIM <50). In this subsample, the treatment group saw larger changes in FIM scores

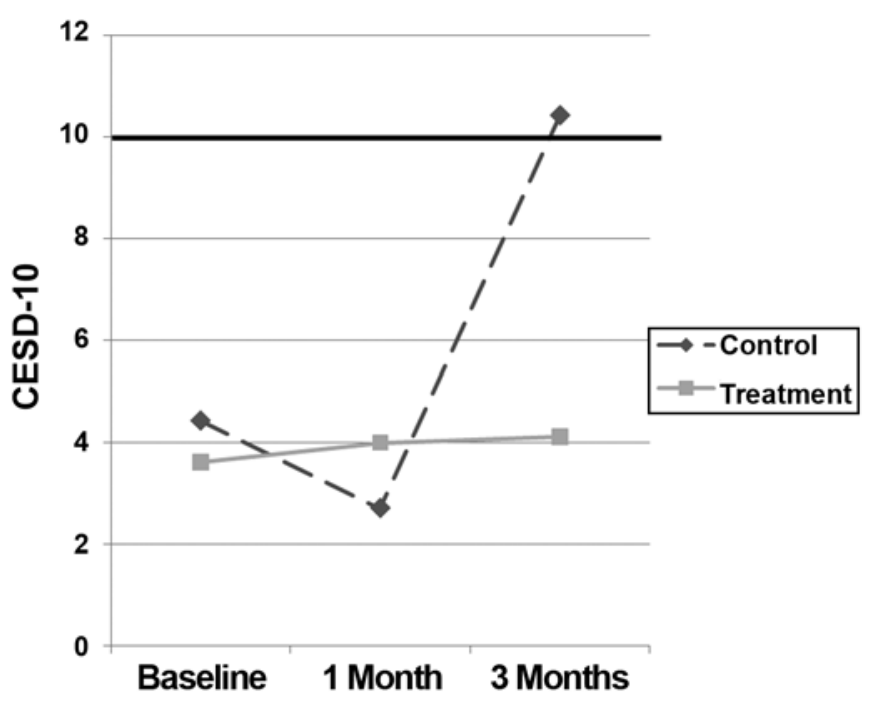

Figure 2.

Depression, as measured by Center for Epidemiologic Studies Depression (CESD-10) scale, scores for caregivers below threshold for depression at baseline by treatment group $(n=27)$. Scores reported for each time frame represent mean scores for each respective group. Graph includes only caregivers who were below threshold of 10 for depression at baseline. Bold line represents threshold value (10) for depression on this instrument.

than did the control group (+20.7 vs +18.3$)$ at the 3- month FONE FIM (Figure 4), although the effect did not achieve traditional levels of statistical significance. This finding may indicate that the effects of the TAP are most likely to occur among veterans with low Motor FIM scores. Although this amount of change may be clinically significant, with the control group displaying a 37.2 percent increase in functional independence and the treatment group displaying a 45.2 percent increase, it is important to emphasize that the differences were not statistically significant and again must be interpreted with caution.

\section{DISCUSSION}

The results of this pilot investigation suggest that, with some reservations, the TAP may be an effective intervention to support stroke caregivers during the transition from hospital to home and further research is warranted. In several analyses, the treatment group exhibited better mental health than the control group at the 3-month follow-up. Caregivers' levels of depression and strain were inversely related to their satisfaction with 
JRRD, Volume 47, Number 7, 2010

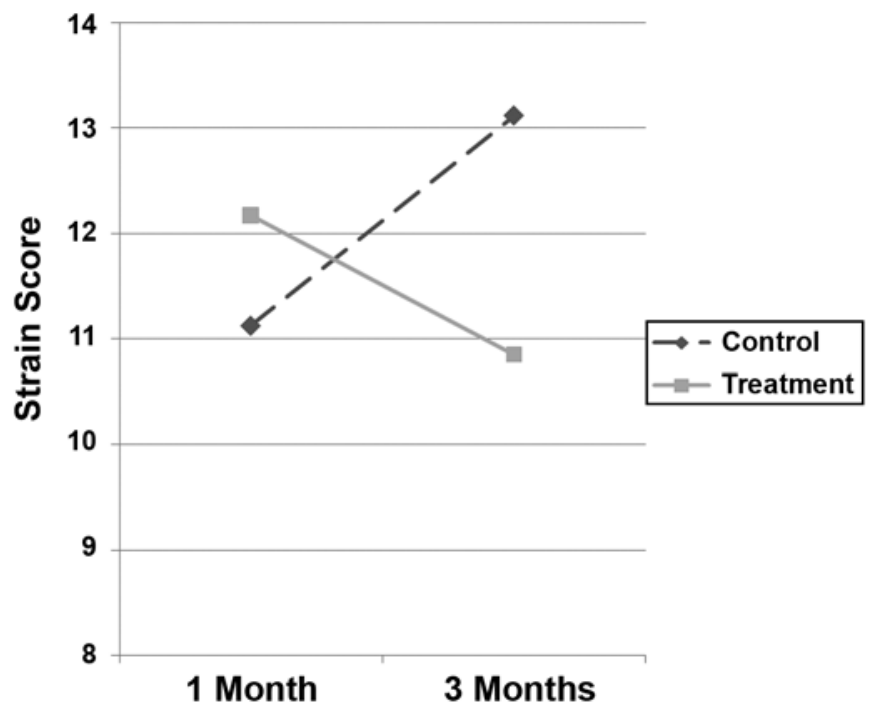

Figure 3.

Strain, as measured by Caregiver Strain Index, scores for total sample by treatment group $(n=61)$. Strain was only measured at 1 and 3 months postdischarge. Score below 7 (not visible) represents "no strain.”

the TAP, and when controlling for baseline differences, we found that the treatment group had lower depression ( $p=0.07)$ than the control group at follow-up. Further, a statistically nonsignificant visual trend emerged for caregivers below the threshold for depression at baseline in that the TAP group did not develop depression at the 3-month follow-up, whereas the control group showed a marked increase in depression. This suggests that the TAP may have a preventative effect on depression for caregivers who are not depressed at discharge, although this finding should be interpreted with caution and further research is needed.

Similarly, the TAP reduced caregiver strain at 3 months, a statistically significant effect, suggesting that it is an effective treatment for strain. A statistically nonsignificant visual trend emerged among veterans with low physical functional independence at baseline in that veterans whose caregivers received the TAP improved on that variable more so than did veterans whose caregivers were in the control group. Also, improved caregiver psychosocial functioning (depression and strain) was related to an improvement in veteran functional status. Though many trends emerged in this study, some statistically significant and some not, more longitudinal data are needed to examine these trends over a longer time period. Taken

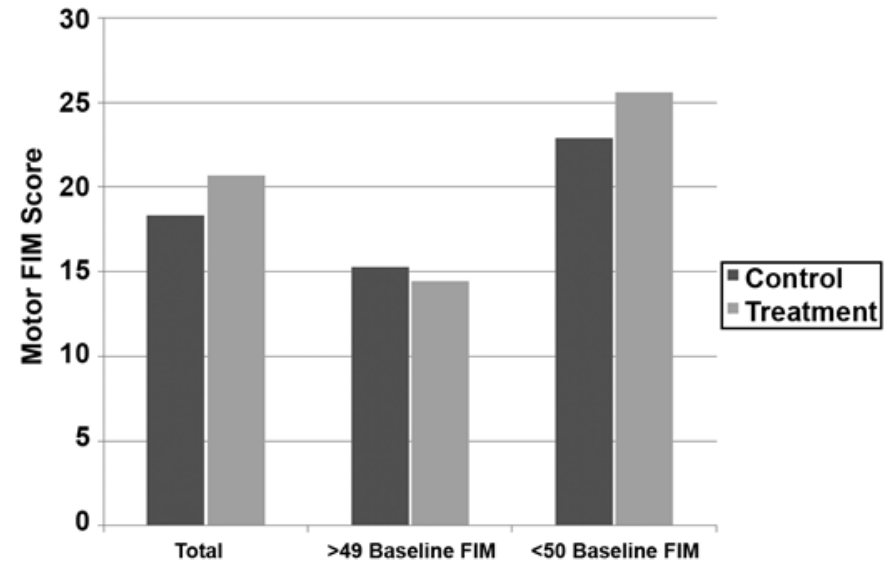

Figure 4.

Average change in functional independence, as measured by Functional Independence Measure (FIM), scores by treatment group and baseline scores. FIM was collected by medical chart at discharge for baseline measure and at 3 months postdischarge during exit interview via adapted FONE FIM instrument (telephone version of FIM).

together, the findings warrant further evaluation of the TAP intervention.

Several limitations apply to this pilot project. First, the duration of the funding period limited the length of time for follow-up measures, and we could only measure the TAP's efficacy at 3 months postdischarge. A longitudinal study would permit a much stronger assessment of the intervention. Research has suggested that the first month postdischarge is one of the most stressful periods for stroke caregivers because that is when the limitations of the individual with stroke become salient [10]. As a result of this process, major changes in caregiver mental health in our study were likely occurring during the 3-month follow-up interval. The TAP intervention could very well influence the trajectory of caregiver mental health differentially across 6 or 12 months after caregiver mental health has stabilized somewhat, as compared with during the first 3 months postdischarge when major changes are still taking place. More thorough longitudinal testing of the TAP's efficacy is critical.

Another limitation of the pilot project is that this was the first testing of the TAP. We learned several things about the intervention that warrant changes in future applications and that may strengthen outcomes of the intervention. For example, we intentionally designed the intervention to be as brief (low dosage) as possible to limit cost of the intervention and to evaluate outcomes of 
a minimum dosage effect. In future applications, we may need to evaluate a stronger dose of the TAP by extending the number of calls and extending the time frame so that the dosage matches the needs of the caregiver rather than arbitrarily ending the TAP. For example, those caregivers with poorer mental health may need a longer intervention or more frequent calls.

In addition, the current study did not compare the efficacy of a videophone versus a traditional telephone. Videophones were used in order to improve communication through visual contact, allow the interventionists and caregivers to pick up on nonverbal communication, help in strategizing regarding the provision of informal care based on a visual presentation of the caregiver's physical environment, and help improve caregiver compliance with and engagement in the treatment. However, in the current study, these were all theoretical reasons, as opposed to scientifically validated reasons, for using videophones rather than traditional telephones. Future research should compare the efficacy in the TAP intervention in these two different mediums.

The sample was limited both to veterans with caregivers who had a landline telephone line and to the number of dyads that we could enroll during the restricted enrollment period at two sites. We were unable to provide the TAP to those with cellular telephones, thus eliminating some veterans who were interested in participating.

\section{CONCLUSIONS}

The current study provides evidence that the TAP is a promising brief intervention for stroke caregivers and further refinement and evaluation are warranted. The following conclusions should be highlighted:

- The TAP is a brief intervention that is highly satisfying to caregivers. This satisfaction is related to the improved caregiver psychosocial outcomes of reduced strain and depression.

- The TAP is an effective support mechanism associated with reduced caregiver strain.

- When controlling for baseline differences, we found that the TAP may be an effective treatment for depression.

- Improved caregiver psychosocial functioning (depression and strain) is related to an improvement in veteran functional status.

\section{ACKNOWLEDGMENTS}

\section{Author Contributions:}

Study concept and design: A. Johnston, B. Vogel, M. Heesacker, M. Rittman.

Acquisition of data: A. Johnston, M. Vega-Trujillo, J. Anderson. Analysis and interpretation of data: P. B. Perrin, M. Heesacker, B. Vogel.

Drafting of manuscript: P. B. Perrin, M. Rittman.

Critical revision of manuscript for important intellectual content:

P. B. Perrin, M. Rittman.

Statistical analysis: P. B. Perrin, B. Vogel, M. Heesacker.

Obtained funding: M. Rittman, B. Vogel, M. Heesacker.

Administrative, technical, or material support: A. Johnston, M. VegaTrujillo, J. Anderson.

Study supervision: M. Rittman.

Financial Disclosures: The authors have declared that no competing interests exist.

Funding/Support: This material is the result of work supported with resources of the Office of Patient Care Services, VA Central Office, Washington, DC.

Institutional Review: This study was approved by the University of Florida Health Science Center Institutional Review Board (IRB) and the VA Research and Development Committee. IRB approval was also obtained at the two pilot sites prior to initiation of the project. Informed consent was obtained from all veterans and caregivers prior to study participation.

Participant Follow-Up: The authors plan to inform participants of the publication of this study.

\section{REFERENCES}

1. American Heart Association. Heart disease and stroke statistics-2005 update [Internet]. Dallas (TX): American Heart Association; 2005. Available from: http://www.americanheart.org/downloadable/heart/ 1105390918119HDSStats2005Update.pdf

2. Gresham GE, Duncan PW, Stason WB, Adams HP, Adelman AM, Alexander DN, Bishop DS, Diller L, Donaldson NE, Holland AL, Kelly-Hayes M, McDowell FH, Myers L, Phipps MA, Roth EJ, Siebens HC, Tarvin GA, Trombly CA. Post-Stroke Rehabilitation: Clinical Practice Guideline, No. 16. Rockville (MD): U.S. Department of Health and Human Services, Public Health Service, Agency for Health Care Policy and Research; 1995. AHCPR publication 95-0662.

3. Spillman BC, Long SK. Does high caregiver stress predict nursing home entry? Inquiry. 2009;46(2):140-61. [PMID: 19694388]

4. Kwon S, Duncan PW, Reker DM, Lai SM, Studenski SA, Perera S, Alfrey C, Marquez J. Measuring health-related quality of life in veterans with stroke. Poster presented at: Department of Veterans Affairs Health Services Research 
and Development Service National Meeting; 2005 Feb 1618; Baltimore (MD).

5. Veterans Health Administration. Veteran healthcare enrollment and expenditure projections. Washington (DC): Office of Policy and Planning (105); 2003.

6. Han B, Haley WE. Family caregiving for patients with stroke. Review and analysis. Stroke. 1999;30(7):1478-85. [PMID: 10390326]

7. Farzan DT. Reintegration for stroke survivors. Home and community considerations. Nurs Clin North Am. 1991;26(4): 1037-48. [PMID: 1945935]

8. Rittman M, Boylstein C, Hinojosa R, Hinojosa MS, Haun J. Transition experiences of stroke survivors following discharge home. Top Stroke Rehabil. 2007;14(2):21-31. [PMID: 17517571] DOI:10.1310/tsr1402-21

9. Rittman MR. Culturally sensitive models of stroke recovery and caregiving after discharge home. Gainesville (FL): Department of Veterans Affairs Health Services Research and Development Service Study, Nursing Research Initiative: HSR\&D Stroke QUERI; 2000. NRI 98-183.

10. Grant JS, Glandon GL, Elliott TR, Giger JN, Weaver M. Caregiving problems and feelings experienced by family caregivers of stroke survivors the first month after discharge. Int J Rehabil Res. 2004;27(2):105-11.

[PMID: 15167107]

DOI:10.1097/01.mrr.0000127639.47494.e3

11. Lee J, Soeken K, Picot SJ. A meta-analysis of interventions for informal stroke caregivers. West J Nurs Res. 2007; 29(3): 344-64. [PMID: 17420524] DOI:10.1177/0193945906296564

12. Grant JS, Elliott TR, Giger JN, Bartolucci AA. Social problemsolving telephone partnerships with family caregivers of persons with stroke. Int J Rehabil Res. 2001;24(3):181-89.

[PMID: 11560233]

DOI:10.1097/00004356-200109000-00003

13. Rodgers H, Atkinson C, Bond S, Suddes M, Dobson R, Curless R. Randomized controlled trial of a comprehensive stroke education program for patients and caregivers. Stroke. 1999;30(12):2585-91. [PMID: 10582982]

14. Van den Heuvel ET, Witte LP, Stewart RE, Schure LM, Sanderman R, Meyboom-de Jong B. Long-term effects of a group support program and an individual support program for informal caregivers of stroke patients: Which caregivers benefit the most? Patient Educ Couns. 2002;47(4):291-99. [PMID: 12135820] DOI:10.1016/S0738-3991(01)00230-0

15. Mant J, Carter J, Wade DT, Winner S. Family support for stroke: A randomised controlled trial. Lancet; 2000;356(9232): 808-13. [PMID: 11022928] DOI:10.1016/S0140-6736(00)02655-6
16. Gallagher-Thompson D, Lovett S, Rose J, McKibbin C, Coon D, Futterman A, Thompson LW. Impact of psychoeducational interventions on distressed family caregivers. J Clin Geropsychol. 2000;6(2):91-110.

DOI:10.1023/A:1009584427018

17. Grant JS, Elliott TR, Weaver M, Bartolucci AA, Giger JN. Telephone intervention with family caregivers of stroke survivors after rehabilitation. Stroke. 2002;33(8):2060-65. [PMID: 12154263] DOI:10.1161/01.STR.0000020711.38824.E3

18. Lutz BJ, Chumbler NR, Lyles T, Hoffman N, Kobb R. Testing a home-telehealth programme for US veterans recovering from stroke and their family caregivers. Disabil Rehabil. 2009;31(5):402-9. [PMID: 18720112] DOI:10.1080/09638280802069558

19. Draper B, Bowring G, Thompson C, Van Heyst J, Conroy P, Thompson J. Stress in caregivers of aphasic stroke patients: A randomized controlled trial. Clin Rehabil. 2007;21(2): 122-30. [PMID: 17264106] DOI:10.1177/0269215506071251

20. Brereton L, Carroll C, Barnston S. Interventions for adult family carers of people who have had a stroke: A systematic review. Clin Rehabil. 2007;21(10):867-84.

[PMID: 17981846] DOI:10.1177/0269215507078313

21. Smith J, Forster A, Young J; Cochrane Group for information provision after stroke. Cochrane review: Information provision for stroke patients and their caregivers. Clin Rehabil. 2009;23(3):195-206. [PMID: 19218295] DOI:10.1177/0269215508092820

22. Eldred C, Sykes C. Psychosocial interventions for carers of survivors of stroke: A systematic review of interventions based on psychological principles and theoretical frameworks. Br J Health Psychol. 2008;13(Pt 3):563-81. [PMID: 17708832] DOI:10.1348/135910707X236899

23. Perrin PB, Heesacker M, Stidham BS, Rittman MR, Gonzalez-Rothi LJ. Structural equation modeling of the relationship between caregiver psychosocial variables and functioning of individuals with stroke. Rehabil Psychol. 2008;53(1):54-62. DOI:10.1037/0090-5550.53.1.54

24. Perrin PB, Heesacker M, Hinojosa MS, Uthe CE, Rittman MR. Identifying at-risk, ethnically diverse stroke caregivers for counseling: A longitudinal study of mental health. Rehabil Psychol. 2009;54(2):138-49. [PMID: 19469603] DOI:10.1037/a0015964

25. Robinson BC. Validation of a Caregiver Strain Index. J Gerontol. 1983;38(3):344-48. [PMID: 6841931]

26. Sullivan MT. The Modified Caregiver Strain Index (CSI). Try This: General Assessment Series. Best Practices in Nursing Care to Older Adults. New York (NY): The Hartford Institute for Geriatric Nursing, New York University, 
College of Nursing; 2002; Available from: http://consultgerirn.org/uploads/File/trythis/try this 14.pdf

27. Andresen EM, Malmgren JA, Carter WB, Patrick DL. Screening for depression in well older adults: Evaluation of a short form of the CES-D (Center for Epidemiologic Studies Depression Scale). Am J Prev Med. 1994;10(2):77-84. [PMID: 8037935]

28. Kilbourne AM, Justice AC, Rollman BL, McGinnis KA, Rabeneck L, Weissman S, Smola S, Schultz R, Whittle J, Rodriguez-Barradas M. Clinical importance of HIV and depressive symptoms among veterans with HIV infection. J Gen Intern Med. 2002;17(7):512-20. [PMID: 12133141] DOI:10.1046/j.1525-1497.2002.10803.x

29. Granger CV, Cotter AC, Hamilton BB, Fiedler RC, Hens MM. Functional assessment scales: A study of persons with multiple sclerosis. Arch Phys Med Rehabil. 1990; 71(11):870-75. [PMID: 2222154]

30. Hamilton BB, Laughlin JA, Fiedler RC, Granger CV. Interrater reliability of the 7-level Functional Independence Measure (FIM). Scand J Rehabil Med. 1994;26(3):115-19. [PMID: 7801060$]$

31. Hamilton BB, Laughlin JA, Granger CV, Kayton RM. Interrater agreement of the seven-level Functional Independence Measure (FIM) [abstract]. Arch Phys Med Rehabil. 1991;72:790.

32. Ottenbacher KJ, Hsu Y, Granger CV, Fiedler RC. The reliability of the Functional Independence Measure: A quantitative review. Arch Phys Med Rehabil. 1996;77(12):1226-32. [PMID: 8976303]

DOI:10.1016/S0003-9993(96)90184-7

33. Dodds TA, Martin DP, Stolov WC, Deyo RA. A validation of the functional independence measurement and its performance among rehabilitation inpatients. Arch Phys Med Rehabil. 1993;74(5):531-36. [PMID: 8489365]

DOI:10.1016/0003-9993(93)90119-U

34. Granger CV, Cotter AC, Hamilton BB, Fiedler RC. Functional assessment scales: A study of persons after stroke. Arch Phys Med Rehabil. 1993;74(2):133-38. [PMID: 8431095]

35. Heinemann AW, Crown D, McMahon R. Utility of the functional assessment inventory in a post-stroke sample. Rehabil Couns Bull. 2000;43(3):165-77.

DOI:10.1177/003435520004300307

36. Heinemann AW, Linacre JM, Wright BD, Hamilton BB, Granger C. Prediction of rehabilitation outcomes with disability measures. Arch Phys Med Rehabil. 1994;75(2): 133-43. [PMID: 8311668]
37. Heinemann AW, Kirk P, Hastie BA, Semik P, Hamilton BB, Linacre JM, Wright BD, Granger C. Relationships between disability measures and nursing effort during medical rehabilitation for patients with traumatic brain and spinal cord injury. Arch Phys Med Rehabil. 1997;78(2):143-49. [PMID: 9041894] DOI:10.1016/S0003-9993(97)90255-0

38. Pollak N, Rheault W, Stoecker JL. Reliability and validity of the FIM for persons aged 80 years and above from a multilevel continuing care retirement community. Arch Phys Med Rehabil. 1996;77(10):1056-61. [PMID: 8857886] DOI:10.1016/S0003-9993(96)90068-4

39. Stineman MG, Shea JA, Jette A, Tassoni CJ, Ottenbacher KJ, Fiedler R, Granger CV. The Functional Independence Measure: Tests of scaling assumptions, structure, and reliability across 20 diverse impairment categories. Arch Phys Med Rehabil. 1996;77(11):1101-8. [PMID: 8931518] DOI:10.1016/S0003-9993(96)90130-6

40. Corrigan JD, Smith-Knapp K, Granger CV. Validity of the functional independence measure for persons with traumatic brain injury. Arch Phys Med Rehabil. 1997;78(8): 828-34. [PMID: 9344301] DOI:10.1016/S0003-9993(97)90195-7

41. Heinemann AW, Roth EJ, Cichowski K, Betts HB. Multivariate analysis of improvement and outcome following stroke rehabilitation. Arch Neurol. 1987;44(11):1167-72. [PMID: 3675249]

42. Petrella RJ, Overend T, Chesworth B. FIM after hip fracture: Is telephone administration valid and sensitive to change? Am J Phys Med Rehabil. 2002;81(9):639-44.

[PMID: 12172514]

DOI:10.1097/00002060-200209000-00001

Submitted for publication November 12, 2009. Accepted in revised form May 4, 2010.

This article and any supplementary material should be cited as follows:

Perrin PB, Johnston A, Vogel B, Heesacker M, VegaTrujillo M, Anderson J, Rittman M. A culturally sensitive Transition Assistance Program for stroke caregivers: Examining caregiver mental health and stroke rehabilitation. J Rehabil Res Dev. 2010:47(7):605-16.

DOI:10.1682/JRRD.2009.10.0170 
616

JRRD, Volume 47, Number 7, 2010 
